\title{
Glucocorticoid Secretion Inhibition
}

National Cancer Institute

\section{Source}

National Cancer Institute. Glucocorticoid Secretion Inhibition. NCI Thesaurus. Code C41505.

Glucocorticoid Secretion Inhibition consists of interference with, or restraint of, activities involved in release into the bloodstream by the adrenal cortex of a class of steroid substances (glucocorticoids) that affect fat, protein, and carbohydrate metabolism (gluconeogenesis, liver glycogen deposition, elevation of blood sugar); inhibit corticotropin secretion; possess anti-inflammatory activity; and play a role in arterial blood pressure, connective tissue response to injury, reduction of circulating lymphocytes, and central nervous system function. Alteration of positive or negative feedback mechanisms can affect hormone release. 